\title{
Analisis mutu air Danau Area Gelanggang Expo dengan metode indeks pencemaran di kota Jayapura
}

\author{
Angga Prasetia ${ }^{1}$, Auldry F. Walukow ${ }^{2 *}$ \\ ${ }^{1}$ Mahasiswa Program Sarjana pada Program Studi Pendidikan Fisika Universitas Cenderawasih \\ ${ }^{2}$ Staf Pengajar Universitas Cenderawasih, Jayapura-Papua \\ *Koresponden E-mail: walukow.auldry@gmail.com
}

(Diterima 29 Aguastus 2020|Disetujui 10 Januari 2021|Diterbitkan 30 Januari 2021)

\begin{abstract}
This study aims to determine the current status of lake water quality in the Gelanggang Expo area using the Pollution Index (IP) method. It is found that there has been pollution in Lake Sentani with high concentrations of certain pollutants, such as Nitrite as NO2-N $(0.06-0.15 \mathrm{mg} / \mathrm{L})$, Phosphate as PO4-P $(0.2-0.45 \mathrm{mg} / \mathrm{L})$, Sulfide as $S$ H2S (0.002 - $4.26 \mathrm{mg} / \mathrm{L})$, Cadmium (0.01 - $0.3 \mathrm{mg} / \mathrm{L})$, Chromium valence $6(0.05-0.26 \mathrm{mg} / \mathrm{L})$, Copper $(0.02-2.15$ $m g / L)$, Zinc $(0.05-0.5 \mathrm{mg} / L)$, Phenolic compounds $(1-9.53 \mu \mathrm{g} / L)$, and free chlorine $(0.03-2,1 \mathrm{mg} / \mathrm{L})$. The concentration of these substances has exceeded the quality standard set by the government through PP 82 of 2001 concerning water quality management and water pollution control. The status of the lake water quality in the Gelanggang Expo area is declared moderately polluted with an IP value of 6.78. Sentani lake pollution is caused by eight parameters that have exceeded the quality standard, namely temperature, $\mathrm{BOD}, \mathrm{COD}$, Sulfide, $\mathrm{Pb}, \mathrm{Cu}$, Phenol, and free chlorine.
\end{abstract}

Keywords: water quality, pollution index, quality standard, the lake in the Gelanggang Expo area.

Danau adalah salah satu sumber daya alam yang sangat potensial jika dikelola dengan baik, antara lain sebagai sumber air bersih, perikanan, transportasi, irigasi dan ekowisata. Sebagian besar wilayah Danau Sentani terletak di Kabupaten Jayapura yaitu Distrik Sentani Timur, Sentani, Sentani Barat, dan sebagian kecil wilayahnya berada di Distrik Abepura Kota Jayapura. Danau ini memiliki luas sekitar 9630 ha dengan kedalaman rata - rata $52 \mathrm{~m}$, dan terletak pada ketinggian $72 \mathrm{~m}$ di atas permukaan laut. Bentuk morfologi Danau Sentani memanjang dari arah timur ke barat sepanjang $26,5 \mathrm{~km}$, dengan lebar bervariasi antara $2-4 \mathrm{~km}$ disekitar selat Simporo, dan lebar maksimal $24 \mathrm{~km}$ di bagian barat dan timur danau (Walukouw,2017).

Namun, Danau Sentani ini telah terjadi pencemaran yang ditandai dengan tingginya pencemaran pada zat-zat tertentu, seperti Nitrit sebagai $\mathrm{NO}_{2}-\mathrm{N}(0,06-0,15 \mathrm{mg} / \mathrm{L})$, Fosfat sebagai $\mathrm{PO}_{4}-\mathrm{P}(0,20-$ $0,45 \mathrm{mg} / \mathrm{L})$, Sulfida sebagai $\mathrm{S}-\mathrm{H}_{2} \mathrm{~S} \quad(0,002-4,260$ $\mathrm{mg} / \mathrm{L})$, Cadmium $(0,01-0,30 \mathrm{mg} / \mathrm{L})$, Chromium valensi $6 \quad(0,05-0,26 \mathrm{mg} / \mathrm{L})$, Tembaga $(0,02-2,15$ $\mathrm{mg} / \mathrm{L})$, Zinc $(0,05-0,50 \mathrm{mg} / \mathrm{L})$, senyawa Fenol (1 $9,53 \mu \mathrm{g} / \mathrm{L})$, dan Chlorine bebas $(0,03-2,10 \mathrm{mg} / \mathrm{L})$, pencemaran zat-zat ini telah melebihi baku mutu yang ditetapkan pemerintah melalui PPRI No 82 Tahun 2001 (Kapisa, 2017).

Adanya pembatasan waktu dikarenakan masalah pencemaran air merupakan sebuah masalah kompleks yang menyangkut berbagai hal. Banyak faktor yang mempengaruhi, seperti aktivitas manusia, diperkirakan membuat tingkat kualitas air danau menjadi rendah (Pradhana, et al., 2014). Salah satu cara untuk mengontrol pencemaran suatu ekosistem dapat dilakukan dengan pemantauan kualitas air dalam jangka waktu tertentu, sehingga di ketahui status mutu perairan tersebut (Kadim, et al., 2017). Permasalahan yang sering terjadi adalah pemanfaatan dan konservasi yang tidak berimbang serta terjadi pemanfaatan danau yang berlebih (over exploited) yang tidak memperhatikan daya dukung. Pendangkalan akibat erosi dan eutrofikasi merupakan penyebab suksesi suatu perairan danau. Hilangnya ekosistem danau mengakibatkan kekurangan cadangan air tanah pada suatu kawasan/wilayah dan akhirnya mengancam ketersediaan air bersih bagi kehidupan manusia dan makhluk hidup lainnya. Akibatnya, lingkungan hidup yang di dalamnya terdapat manusia dan alam terancam tidak dapat berlanjut. Pencemaran air berdampak pada suplai air minum, ekosistem, ekonomi serta kesehatan manusia dan keamanan sosial (social security).

Zat atau bahan yang dapat mengakibatkan pencemaran disebut polutan. Syarat-syarat suatu zat disebut polutan bila keberadaannya dapat menyebabkan kerugian terhadap makhluk hidup.

Ditinjau dari asal polutan dan sumber pencemarannya, pencemaran air dapat dibedakan antara lain 1) limbah pertanian; 2) limbah rumah tangga; 3) limbah industri; 4) penangkapan ikan menggunakan racun. Akibat yang ditimbulkan oleh pencemaran air antara lain a) terganggunya kehidupan organisme air karena berkurangnya kandungan oksigen; b) terjadinya ledakan populasi ganggang dan tumbuhan air (eutrofikasi); dan c) pendangkalan dasar perairan.

Menurut Walukow, (2011) beberapa permasalahan di sekitar Danau Sentani adalah kerusakan daerah tangkapan air danau, lahan kritis dan pembukaan hutan serta penurunan kualitas air danau pada beberapa lokasi. Luas laha kritis di DAS Sentani sekitar 21.292 ha atau sekitar $26 \%$ dari total catchmen area. Laju pengendapan (sedimentasi) di Danau Sentani mencapai 90 ton per tahun. Erosi 
tanah yang memasuki badan air dapat menimbulkan dampak positif, yakni peningkatan kandungan unsur hara di perairan. Namun di sisi lain, erosi tanah juga dapat menimbulkan dampak negatif terhadap kualitas perairan, antara lain penurunan nilai kecerahan serta peningkatan nilai kekeruhan dan padatan tersuspensi. Oleh sebab itu, dibutuhkan kajian dan pengelolaan Danau Sentani sehingga dapat berkelanjutan.

\section{BAHAN DAN METODE}

Metode penelitian yang digunakan adalah metode survey dengan sifat deskriptif kuantitatif. Pengambilan sampel pada tanggal 23 Mei 2019 pukul 10.15 WIT, lalu penerimaan data pada tanggal $23 \mathrm{Mei}$
2019 pukul 17.15 WIT, dan pengujian data pada tanggal 24 Mei 2019 pukul 09.00 WIT s/d selesai.

Penelitian dilaksanakan di area Gelanggang Expo, Kota Jayapura yang beriklim tropis dengan suhu maksimum pada siang hari $32,2^{\circ} \mathrm{C}$, suhu minimum pada malam hari $23,6^{\circ} \mathrm{C}$, dan temperatur rata-rata hariannya $27,6^{\circ} \mathrm{C}$.

Metode penentuan stasiun dalam pengambilan sampel air dilakukan dengan purposive sampling yaitu penentuan stasiun pengamatan dilakukan dengan memperhatikan berbagai pertimbangan kondisi dan keadaan tempat penelitian seperti kondisi aktivitas di darat, pemukiman, dan inlet sungai yang diduga berpengaruh terhadap kualitas air danau.

Analisis kualitas air danau menggunakan klasifikasi mutu air kelas dua.

Parameter yang diukur meliputi sifat fisika, kimia dan mikrobiologi (Tabel 1).

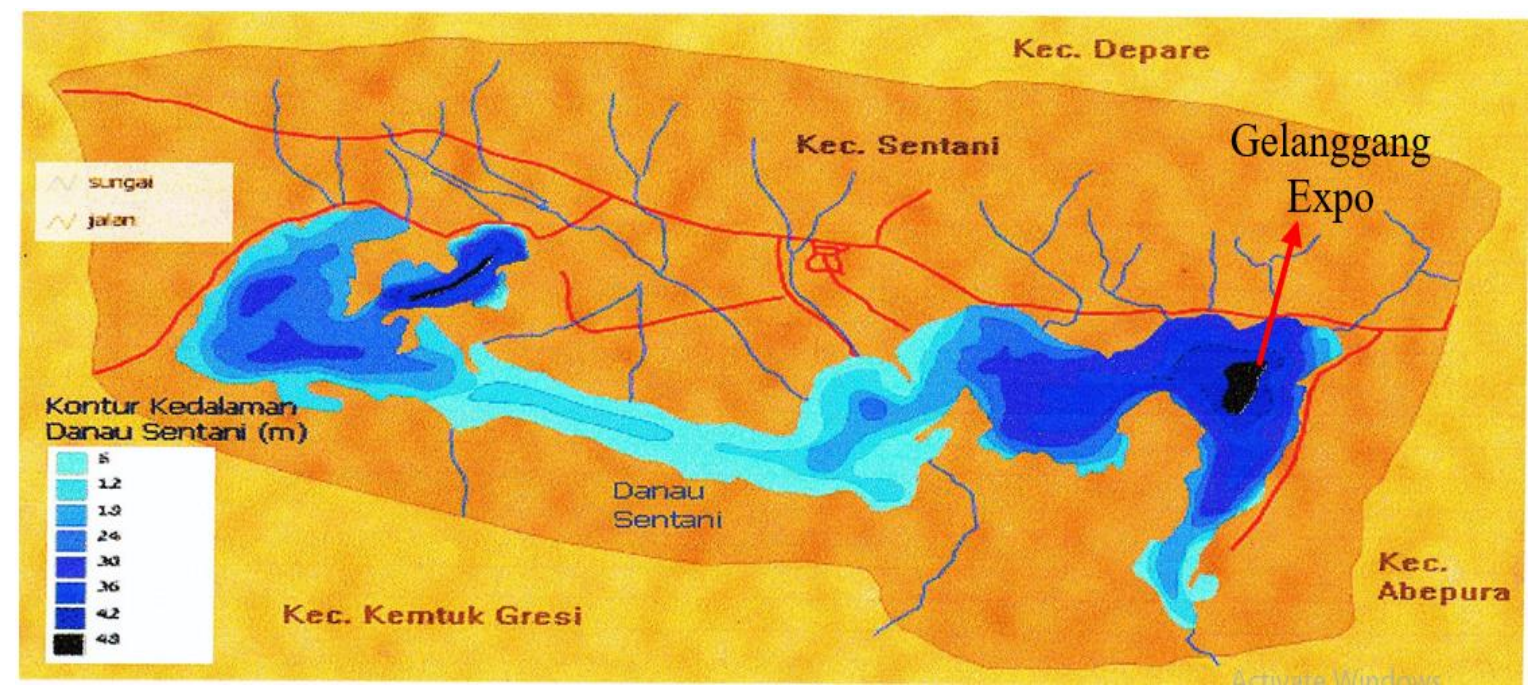

Gambar 1. Lokasi Penelitian

Tabel 1. Metode Analisis Laboratorium Parameter Fisika, Kimia, dan Mikrobiologi.

\begin{tabular}{|c|c|c|c|c|}
\hline No & Parameter & Satuan & Alat & Metode \\
\hline & Fisika: & & & \\
\hline 1. & Suhu & ${ }^{\circ} \mathrm{C}$ & Termometer Hg & SNI 06-2413-1991 \\
\hline 2. & Kecerahan & $\mathrm{m}$ & Secchi disk & SNI 06-2413-1991 \\
\hline \multirow[t]{2}{*}{3.} & TDS & $\mathrm{mg} / \mathrm{L}$ & $\begin{array}{l}\text { Penyaring milipore, timbangan } \\
\text { analitik }\end{array}$ & SNI 06-2413-1991 \\
\hline & Kimia: & - & $\mathrm{nH}$ meter & SNI 06-2413-1991 \\
\hline 5. & DO & $\mathrm{mg} / \mathrm{L}$ & Peralatan titrasi/DO meter & SNI 06-2413-1991 \\
\hline 6. & $\mathrm{BOD}_{5}$ & $\mathrm{mg} / \mathrm{L}$ & Peralatan titrasi & SNI 06-2413-1991 \\
\hline 7. & COD & $\mathrm{mg} / \mathrm{L}$ & Peralatan titrasi & $\begin{array}{l}\text { Standar method 2005, Section } \\
5220 . \mathrm{B}\end{array}$ \\
\hline 8. & Ammonia & $\mathrm{mg} / \mathrm{L}$ & Peralatan titrasi & SNI 06-2480-1991 \\
\hline 9. & Klorida & $\mathrm{mg} / \mathrm{L}$ & Peralatan titrasi & Titrasi, laboratorium \\
\hline 10. & Flourida & $\mathrm{mg} / \mathrm{L}$ & Peralatan titrasi & Titrasi, laboratorium \\
\hline 11. & Nitrat & $\mathrm{mg} / \mathrm{L}$ & Peralatan titrasi & SNI 06-2480-1991 \\
\hline 12. & Nitrit & $\mathrm{mg} / \mathrm{L}$ & Peralatan titrasi & SNI 06-2480-1991 \\
\hline 13. & Phosfat & $\mathrm{mg} / \mathrm{L}$ & Peralatan titrasi & $\begin{array}{l}\text { Standar method 2005, Section } \\
4500-\mathrm{No}_{2} . \mathrm{B}\end{array}$ \\
\hline 14. & Sulfat & $\mathrm{mg} / \mathrm{L}$ & Peralatan titrasi & SNI 06-2413-1991 \\
\hline 15. & Sulfida & $\mathrm{mg} / \mathrm{L}$ & Peralatan titrasi & SNI 06-2413-1991 \\
\hline 16. & Arsen & $\mathrm{mg} / \mathrm{L}$ & Peralatan titrasi & SNI 06-2413-1991 \\
\hline
\end{tabular}


17. Besi

18. Kadmium

19. Kromium

20. Kobalt

21. Mangan

22. Merkuri

23. Timbal

24. Tembaga

25. Zink

26. Detergen(MBAS)

27. Minyak/Lemak

28. Senyawa Fenol

29. Klorin Bebas

Mikrobiologi

30. Fecal Coliform

31. Total Coliform
mg/L Peralatan titrasi

mg/L Peralatan titrasi

mg/L Peralatan titrasi

mg/L Peralatan titrasi

mg/L Peralatan titrasi

mg/L Peralatan titrasi

mg/L Peralatan titrasi

mg/L Peralatan titrasi

mg/L Peralatan titrasi

$\mu g / L \quad$ Peralatan titrasi

$\mu g / L \quad$ Peralatan titrasi

$\mu g / \mathrm{L} \quad$ Peralatan titrasi

$\mu \mathrm{g} / \mathrm{L} \quad$ Peralatan titrasi
SNI 06-2413-1991

SNI 06-2413-1991

SNI 06-2413-1991

SNI 06-2413-1991

SNI 06-2413-1991

SNI 06-2413-1991

SNI 06-2413-1991

SNI 06-2413-1991

SNI 06-2413-1991

SNI 06-2469-1991

SNI 06-2469-1991

SNI 06-2469-1991

Standar method 2005, Section 4500-Cl.G

Visual

Visual
Penentuan lokasi sampling ini didasarkan pada aspek-aspek 1) tujuan pengambilan sampel, 2) jenis sumber air yang akan disampel, 3) pola aliran air yang akan disampel dan 4) pola aliran air badan air yang akan disampel, khususnya air permukaan. Posisi (lintang-bujur) lokasi sampling atau masing-masing stasiun pengamatan ditentukan dengan menggunakan GPS (Global Posisioning System) (Walukow, 2016).

Untuk menentukan status mutu air danau area Gelanggang Expo digunakan Metode Indeks Pencemaran (IP). Metode IP merupakan salah satu metode yang digunakan untuk menentukan tingkat pencemaran relatif terhadap parameter kualitas air yang diijinkan. Metode IP ditentukan untuk suatu peruntukkan, kemudian dapat dikembangkan untuk beberapa peruntukkan bagi seluruh bagian badan air atau sebagai dari suatu sungai. Penentuan status mutu air ini berdasarkan pada analisis parameter fisika, kimia, dan biologi. Kualitas air yang baik akan sesuai dengan peraturan yang dikeluarkan pemerintah tersebut dengan kadar (konsentrasi) maksimum yang diperbolehkan. Kualitas air dinilai berdasarkan sistem indeks pencemaran yang mengklasifikasi mutu air ke dalam empat kategori, yaitu:

(1) $0 \leq \mathrm{P}_{\mathrm{ij}} \leq 1,0 \quad$ (memenuhi baku mutu)

(2) $1,0<\mathrm{P}_{\mathrm{ij}} \leq 5,0$ (tercemar ringan)

(3) $5,0<\mathrm{P}_{\mathrm{ij}} \leq 10$ (tercemar sedang)

(4) $\mathrm{P}_{\mathrm{ij}}>10 \quad$ (tercemar berat)

Penentuan status mutu air dengan menggunakan metode IP mengacu pada (Sahabuddin, 2014) dapat dilakukan dengan langkah-langkah:

(a) Pengumpulan data konsentrasi parameter pencemar $\left(\mathrm{C}_{\mathrm{i}}\right)$

(b) Penentuan baku mutu $\left(\mathrm{L}_{\mathrm{ij}}\right)$

(c) Penghitungan nilai $\left(\mathrm{C}_{\mathrm{i}} / \mathrm{L}_{\mathrm{ij}}\right)$. Jika nilai $\left(\mathrm{C}_{\mathrm{i}} / \mathrm{L}_{\mathrm{ij}}>1,0\right)$, maka; gunakan persamaan $\left(\mathrm{C}_{\mathrm{i}} / \mathrm{L}_{\mathrm{ij}}\right)_{\text {baru }}=1,0+5$ LOG $\left(\mathrm{C}_{\mathrm{i}} / \mathrm{L}_{\mathrm{ij}}\right)_{\text {perhitungan }}$ (berlaku semua parameter). Selain itu ada beberapa parameter yang menggunakan

$$
\begin{aligned}
& \frac{C_{i}}{L_{i j}}=\frac{C_{i}-L_{i j \text { rata-rata }}}{L_{i j \text { minimum }}-L_{i j \text { rata-rata }}} \\
& >\text { Jika nilai } \mathrm{C}_{\mathrm{i}}>\mathrm{L}_{\mathrm{ij} \text { rata-rata }} \\
& \frac{C_{i}}{L_{i j}}=\frac{C_{i}-L_{i j \text { rata-rata }}}{L_{i j \text { maksimum }}-L_{i j \text { rata-rata }}} \\
& \mathrm{C}_{\mathrm{ij}}=\mathrm{DO} \text { jenuh }=7 \\
& \frac{C_{i}}{L_{i j}}=\frac{C_{i m}-C_{i \text { pengukuran }}}{C_{i m}-L_{i j}}
\end{aligned}
$$

Indeks pencemaran digunakan untuk mengetahui tingkat pencemaran. Menghitung indeks pencemaran harus ditentukan terlebih dahulu hasil pengukuran konsentrasi parameter pencemaran yaitu yang diteliti langsung di danau. Perumusan indeks pencemaran yaitu sebagai berikut:

$P_{i j}=\sqrt{\frac{\left(\frac{C_{i}}{L_{i j}}\right)_{M}^{2}+\left(\frac{C_{i j}}{L_{i j}}\right)_{R}^{2}}{2}}$

Dimana:

$\mathrm{P}_{\mathrm{ij}} \quad=$ indeks pencemaran

$\mathrm{C}_{\mathrm{i}}=$ hasil pengukuran konsentrasi parameter pencemaran

$\mathrm{L}_{\mathrm{ij}} \quad=$ baku mutu

$\mathrm{R} \quad=$ rata-rata

$\mathrm{M} \quad=$ maksimum 


\section{HASIL}

Tabel 2. Indeks pencemaran air danau area Gelanggang Expo, Kota Jayapura

\begin{tabular}{|c|c|c|c|c|c|}
\hline NO & Parameter & $\begin{array}{l}\text { Baku Mutu } \\
\text { Kelas II } \\
\text { (Lij) }\end{array}$ & $\mathrm{Ci}$ & $\mathrm{Ci} / \mathrm{Lij}$ & (Ci/Lij)baru \\
\hline 1 & Suhu $\left(\mathrm{C}^{\circ}\right)$ & 29 & 29,6 & 1,02 & 1,04 \\
\hline 2 & TDS (mg/L) & 1000 & 69 & 0,06 & 0,06 \\
\hline 3 & TSS (mg/L) & 50 & 38 & 0,76 & 0,76 \\
\hline 4 & $\mathrm{pH}$ & $(6-9),(7.5)$ & 8,14 & 0,42 & 0,42 \\
\hline 5 & $\mathrm{DO}(\mathrm{mg} / \mathrm{L})$ & $\geq 6$ & 6,1 & 0,9 & 0,9 \\
\hline 6 & $\mathrm{BOD}(\mathrm{mg} / \mathrm{L})$ & 2 & 4 & 2 & 2,50 \\
\hline 7 & $\mathrm{COD}(\mathrm{mg} / \mathrm{L})$ & 10 & 25 & 2,5 & 2,98 \\
\hline 8 & $\begin{array}{l}\text { Ammonia sebagai (NH3-N) } \\
(\mathrm{mg} / \mathrm{L})\end{array}$ & 0,5 & 0,31 & 0,62 & 0,62 \\
\hline 9 & Chlorida (mg/L) & 600 & 6,2 & 0,01 & 0,01 \\
\hline 10 & Flourida (mg/L) & 0,5 & 0,19 & 0,38 & 0,38 \\
\hline 11 & Nitrat sebagai (NO3-N) (mg/L) & 10 & 0,7 & 0,07 & 0,07 \\
\hline 12 & Nitrit sebagai (NO2-N) (mg/L) & 0,06 & 0,01 & 0,13 & 0,13 \\
\hline 13 & Phosphat sebagai (PO4-P) (mg/L) & 0,2 & 0,15 & 0,75 & 0,75 \\
\hline 14 & Sulfat $(\mathrm{mg} / \mathrm{L})$ & 400 & 3 & 0,0075 & 0,0075 \\
\hline 15 & Sulfida (mg/L) & 0,002 & 0,008 & 4 & 4,01 \\
\hline 16 & Arsen (mg/L) & 0,05 & 0 & 0 & 0 \\
\hline 17 & Besi (mg/L) & 0,3 & 0,042 & 0,14 & 0,14 \\
\hline 18 & Cadmium (mg/L) & 0,01 & 0,002 & 0,2 & 0,2 \\
\hline 19 & Chromium (mg/L) & 0,05 & 0,024 & 0,48 & 0,48 \\
\hline 20 & Cobalt (mg/L) & 0,02 & 0,004 & 0,2 & 0,2 \\
\hline 21 & Mangan $(\mathrm{mg} / \mathrm{L})$ & 0,1 & 0,012 & 0,12 & 0,12 \\
\hline 22 & Mercury (mg/L) & 0,001 & 0 & 0 & 0,00 \\
\hline 23 & Timbal (mg/L) & 0,03 & 0,06 & 2 & 2,50 \\
\hline 24 & Tembaga $(\mathrm{mg} / \mathrm{L})$ & 0,02 & 0,047 & 2,35 & 2,85 \\
\hline 25 & Detergen sebagai MBAS $(\mu \mathrm{g} / \mathrm{L})$ & 200 & 35 & 0,17 & 0,17 \\
\hline 26 & Minyak/Lemak $(\mu \mathrm{g} / \mathrm{L})$ & 1000 & 258 & 0,25 & 0,25 \\
\hline 27 & Zinc $(\mathrm{mg} / \mathrm{L})$ & 0,05 & 0,035 & 0,7 & 0,7 \\
\hline 28 & $\begin{array}{l}\text { Senyawa Fenol sebagai Fenol } \\
(\mu \mathrm{g} / \mathrm{L})\end{array}$ & 1 & 51 & 51 & 9,53 \\
\hline 29 & Chlorine Bebas (mg/L) & 0,03 & 0,06 & 2 & 2,50 \\
\hline 30 & Fecal Coliform (MPN/100 mL) & 100 & 0 & 0 & 0 \\
\hline 31 & Total Coliform (MPN/100 mL) & 1000 & 0 & 0 & 0 \\
\hline$\sum$ & & & & & 34,35 \\
\hline (Ci/Lij)M & & & & & 9,53 \\
\hline (Ci/Lij)R & & & & & 1,10 \\
\hline Pij & \multicolumn{4}{|c|}{ Tercemar Sedang } & 6,78 \\
\hline
\end{tabular}

Indeks pencemaran dapat diperoleh dari hasil pengukuran konsentrasi parameter pencemaran yang diamati dan dianalisis dalam laboratorium dan baku mutu yang mengacu pada PP 82 tahun 2001 tentang pengelolaan kualitas air dan pengendalian pencemaran air. Konsentrasi parameter pencemaran yang diamati adalah parameter fisika, kimia anorganik bukan logam, kimia anorganik logam terlarut, kimia organik, desinfektan, dan mikrobiologi air.

Indeks pencemaran pada air danau area Gelanggang Expo disebabkan oleh 8 parameter yang telah melebihi baku mutu yaitu parameter suhu, BOD, 
COD, Sulfida, $\mathrm{Pb}, \mathrm{Cu}$, Fenol, dan Chlorine bebas. Sehingaa, status mutu air danau di area Gelanggang Expo telah masuk dalam kategori tercemar sedang dengan nilai IP yaitu 6,78.

\section{PEMBAHASAN}

Hasil pengamatan secara visual terdapat limbah domestic yang terbawa melalui sungai Kampwolker dan akhirnya mecemari air danau di area gelanggang Expo. Oleh karena Gelanggang Expo berdekatan dengan Terminal anggkutan, pemukiman penduduk, cucian mobil, bengkel mobil, bengkel ganti oli kendaraan dan pasar Expo. Pada umumnya limbah domesik yang diamati adalah sampah botol plastic, dedaunan, kaleng, kayu, botol kaca, limbah cair rumah tangga).

Suhu Perairan. Suhu merupakan faktor yang berperan dalam ekosistim perairan. Hasil analisis kualitas air menunjukkan bahwa pengukuran suhu $29,6^{\circ} \mathrm{C}$, kondisi suhu perairan danau ini telah melebihi baku mutu sebesar $29^{\circ} \mathrm{C}$. Hal ini disebabkan oleh banyaknya limbah domestik yang mencemari perairan danau.

BOD. Konsentrasi BOD atau kebutuhan oksigen biologi merupakan salah satu indikator tingginya kandungan bahan organik diperairan. Hasil analisis nilai BOD $4 \mathrm{mg} / \mathrm{L}$, hal ini telah melebihi baku mutu sebesar $2 \mathrm{mg} / \mathrm{L}$. Sumber pencemaran BOD kemungkinan berasal dari limbah domestic dan erosi.

COD. Merupakan jumlah oksigen yang diperlukan agar bahan buangan yang ada di dalam air dapat teroksidasi melalui reaksi kimia. Hasil analisis nilai COD $25 \mathrm{mg} / \mathrm{L}$, hal ini telah melebihi baku mutu sebesar $10 \mathrm{mg} / \mathrm{L}$. Sumber pencemaran COD berasal dari sampah dan air limbah domestic.

Sulfida. Hasil analisis nilai Sulfida $0,008 \mathrm{mg} / \mathrm{L}$, hasil ini telah melebihi baku mutu sebesar 0,002 mg/L. Sumber pencemaran Sulfida kemungkinan berasal dari sampah dan air limbah domestic seperti urin.

Timbal. Hasil analisis nilai Timbal $0,06 \mathrm{mg} / \mathrm{L}$, hasil ini telah melebihi baku mutu sebesar 0,03 mg/L. Sumber utama pencemaran $\mathrm{Pb}$ kemungkinan dari limbah cair bahan bakar minyak (BBM), peralatan rumah tangga seperti sendok, garpu dan pisau serta zat warna kosmetik.

Tembaga. Hasil analisis nilai Tembaga 0,047 $\mathrm{mg} / \mathrm{L}$, hasil ini telah melebihi baku mutu sebesar 0,02 $\mathrm{mg} / \mathrm{L}$. Sumber pencemaran $\mathrm{Cu}$ kemungkinan berasal dari pengikisan (erosi) dari batuan mineral secara alamiah.

Fenol. Senyawa Fenol atau asam Karbolat Benzenol adalah salah satu jenis zat kristal tak berwarna yang memiliki bau khas. Senyawa Fenol merupakan salah satu pencemaran air yang berbahaya bagi ekosistem hayati, sebagaimana kita ketahui bahwa senyawa tersebut bersifat toksik dan mudah larut dalam air sehingga senyawa tersebut dan turunannya dengan mudah menimbulkan pencemaran di alam. Hasil analisis nilai Fenol 51 $\mathrm{mg} / \mathrm{L}$, hasil ini telah melebihi baku mutu sebesar 1 $\mathrm{mg} / \mathrm{L}$.
Senyawa Fenol dalam badan air sungai menyebabkan penyimpangan reproduksi pada zooplankton dan invertebrate yang merupakan kelompok sumber makanan bagi ikan dan dapat menyebabkan kerusakan genetik dan gangguan sistem kekebalan tubuh pada ikan, sehingga dapat menyebabkan kematian pada ikan.

Chlorine Bebas. Hasil analisis nilai Chlorine Bebas $0,06 \mathrm{mg} / \mathrm{L}$, hasil ini telah melebihi baku mutu sebesar 0,03 mg/L. Klorin diduga beral dari limbah domestic.

Hasil penelitian ini sejalan dengan (Walukow, $A$. 2013), (Patty, et al., 2015), \& (Sheftiana, et al., 2017) mengemukakan bahwa kandungan Phosphat yang tinggi dalam badan air dapat menyebabkan kerusakan genetik sampai kematian pada populasi ikan yang hidup di area tersebut. Sumber alamiah fosfat itu sendiri berasal dari pelapukan batuan mineral dan dekomposisi bahan organik. Oleh karena itu, penelitian ini dilaksanakan untuk mengetahui indeks pencemaran danau dengan tepat yaitu menentukan titik sampling, pengambilan data (sampel air danau dan pengukuran parameter pencemaran air), dan pengolahan data laboratorium untuk menentukan hasil parameter pencemaran, serta dimana pengambilan data tersebut akan diuji berdasarkan baku mutu masing-masing parameter.

Penelitian ini diperkuat oleh penelitian Walukow, (2011c) \& Walukow, (2012) yang menyebutkan bahwa pertambahan jumlah penduduk ternyata berdampak pada peningkatan pencemaran yang bersumber dari limbah domestic seperti limbah budidaya KJA, limbah ternak, dan limbah feses manusia. Strategi - strategi yang dapat adalah dengan memanfaatkan sampah atau barang bekas dengan konsep reduce, reuse dan recycle - $3 \mathrm{R}$ (Walukow, 2013). Menurut Walukow, (2011a) menyebutkan bahwa Lembaga kunci dalam pengelolaan Danau Sentani adalah Dinas kelautan dan Perikanan, Dinas Pemukiman, Tokoh Adat/Lembaga Adat, Dinas Lingkungan Hidup dan Kebersihan, Dinas Tata Ruang, Perguruan Tinggi dan Dinas Parawisata.

\section{SIMPULAN}

Hasil analisis status pencemaran air di area Gelanggang Expo tercemar sedang dengan nilai Indeks Pencemaran sebesar 6,78. Terdapat 8 parameter yang telah melebihi baku mutu yaitu parameter suhu, BOD, $\mathrm{COD}$, Sulfida, $\mathrm{Pb}, \mathrm{Cu}$, Fenol, dan Chlorine bebas. Sumber pencemar utama adalah dari limbah domestik dan pencemaran secara alamiah.

\section{UCAPAN TERIMA KASIH}

Ucapan terima kasih kepada semua pihak yang telah memfasilitasi penelitian ini. Selanjutnya kepada pemerintah Kabupaten Jayapura yang terkait di lokasi penelitian ini. 


\section{DAFTAR PUSTAKA}

Kadim, M.K., \& Pasinggi, N. (2017). Kajian Kualitas Perairan Teluk Gorontalo dengan menggunakan Metode STORET. Jurnal Ilmu-ilmu Perairan, Pesisir, dan Perikanan. 6(3), 235-241. DOI: https://doi.org/10.13170/depik.6.3.8442

Patty, S.I., Arfah, H., \& Abdul, M.S. (2015). Zat Hara (Fosfat, Nitrat), Oksigen Terlarut dan $\mathrm{pH}$ Kaitannya dengan Kesuburan di Perairan Jikumerasa, Pulau Buru. Jurnal Pesisir dan Laut Tropis. 1(1): 43-50. DOI: https://doi.org/10.35800/jplt.3.1.2015.9578

Pradhana, A., Sutrisno, E., \& Nugraha, W.D. (2014). Analisis Kualitas Air Sungai Bringin Kota Semarang Menggunakan Metode Indeks Pencemaran. 1-14.

Sahabuddin, H., Harisuseno, D., \& Yuliani, E. (2014). Analisis Status Mutu Air dan Daya Tampung Beban Pencemaran Sungai Wanggu Kota Kendari. Jurnal Teknik Pengairan. 5 (1), 19-28.

Sheftiana, U.S., Sarminingsih, A. \& Nugraha, W.D. (2017). Penentuan Status Mutu Air Sungai Berdasarkan Metode Indeks Pencemaran sebagai Pengendalian Kualitas Lingkungan (Studi Kasus: Sungai Gelis, Kabupaten Kudus, Jawa Tengah). Jurnal Teknik Lingkungan. 6 (1), 1-10.

Kapisa, N. (2017). Kondisi Kenaikan Permukaan Danau Sentani 2016-2017. BPLH Propinsi Papua.

Undang-Undang Pokok Pengelolaan Lingkungan Hidup No. 4 Th. (1982), tentang Pengertian Polusi atau Pencemaran Lingkungan.

Walukow. (2017b). Analysis of Pb Levels as Pollutant in the Waters of the Sentani Lake, JayapuraIndonesia: Study of Determining Water Quality. Journal Der Pharma Chemica, 2017, 9(18),6-8. CODEN (USA): PCHHAX,
Walukow, A. F. (2013). Memanfaatkan Barang Bekas Menjadi Alat Peraga IPA Sederhana Berwawasan Lingkungan Guna Mendukung Model Pembelajaran Kooperatif Dengan Metode Investigasi Kelompok. Jurnal IIlmu Pendidikan Indonesia. $\quad 1(1), \quad 7-14 . \quad$ DOI: https://doi.org/10.31957/jipi.v1i1.322

Walukow, A.F. (2011c). Dampak Pertumbuhan Penduduk Terhadap Beban Sumber PencemarDi Danau Sentani Dengan Model Sistem Dinamik Berwawasan Lingkungan. Jurnal Purifikasi. 12(2), 63-74. https://doi.org/10.12962/j25983806.v12.i2.205

Walukow, A.F. (2012). Analisis Kebijakan Penurunan Luas Hutan Di Daerah Aliran Sungai Sentani Berwawsan Lingkungan. Jurnal Manusia dan Lingkungan. 19(1),74-84. https://doi.org/10.22146/jml.18455

Walukow, A. (2013). Dampak Eutrofikasi Terhadap Ekosistim Perairan. Novae Guinea Jurnal Biologi. 5(1), 462-470.

Walukow, A.F. (2011a). Analisis Tujuan Pengelolaan dan Kebutuhan Dalam Pengembangan Danau Sentani Jayapura. Jurnal Bumi Lestari Pusat Penelitian Lingkungan Hidup Universitas Udayana. ISSN 1411-9668, 11 (1), 120-130.

Walukow, A.F. (2011b). Kondisi Parameter Biologi Plankton dan Ikan di Perairan Danau Sentani Berwawasan Lingkungan. Jurnal Biologi Indonesia, 7 (1), 187-193. Juni 2011, https://doi.org/10.14203/jbi.v7i1.3138

Walukow, A.F. (2016). Analysis of metal concentrations of copper $(\mathrm{Cu})$ in water at sentani lake in jayapura - papua. Journal Der Pharmacia Lettre. 2016, 8 (2), 303-308, Scholars Research Library.

Walukouw, A.F. (2017). Analysis of Pb Levels as Pollutant in the Waters of the Sentani Lake, Jayapura-Indonesia: Study of Determining Water Quality. Journal Der Pharma Chemica. 9(18):6-8. 